\title{
Bleeding Complications in Acute Liver Failure
}

\section{R. Todd Stravitz ${ }^{*}$, Caitlyn Ellerbe ${ }^{2}$, Valerie Durkalski ${ }^{2}$, Michael Schilsky ${ }^{3}$, Robert J. Fontana ${ }^{4}$, Carolyn Peterseim², William M. Lee ${ }^{5}$, and the Acute Liver Failure Study Group}

${ }^{1}$ Hume-Lee Transplant Center of Virginia Commonwealth University, Richmond, VA ${ }^{2}$ Department of Biostatistics, Medical University of South Carolina, Charleston, SC ${ }^{3}$ Division of Gastroenterology and Hepatology, Yale University, New Haven, CT ${ }^{4}$ Division of Gastroenterology, University of Michigan, Ann Arbor, MI

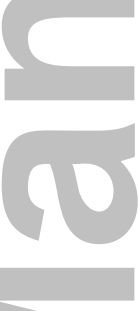

${ }^{5}$ University of Texas-Southwestern Medical Center, Dallas, TX

Keywords: Hemostasis, coagulopathy, transfusion, acetaminophen, intracranial pressure monitor.

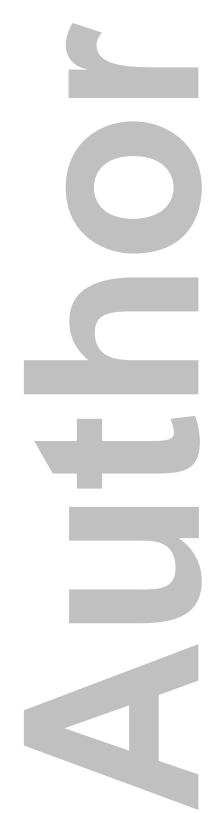

This is the author manuscript accepted for publication and has undergone full peer review but has not been through the copyediting, typesetting, pagination and proofreading process, which may lead to differences between this version and the Version of record. Please cite this article as doi:10.1002/ hep.29694. 


\section{Address Correspondence:}

*Professor of Medicine

Medical Director of Liver Transplantation

Hume-Lee Transplant Center of

Virginia Commonwealth University

PO Box 980341

Richmond, VA 23298-0341

Tel: (804) 828-8514

Fax:

(804) 828-4945

E-mail:

Richard.Stravitz@VCUHealth.ORG

\section{Abbreviations.}

ALF, acute liver failure

APAP, acetaminophen

$\mathrm{ICP}$, intracranial pressure

ICU, intensive care unit

INR, International Normalized Ratio of the prothrombin time

LT, liver transplantation

NAC, $N$-acetylcysteine

$\mathrm{RBC}$, red blood cell

rFVIIa, recombinant Factor VIIa

RRT, renal replacement therapy

SIRS, systemic inflammatory response syndrome

SRMD, stress-related mucosal disease

TFS, transplant-free survival/survivors

UGI, upper gastrointestinal

Funding Source. The Acute Liver Failure Study Group receives funding from the National Institutes of Health/National Institute of Diabetes, Digestive and Kidney Diseases Grant U-01 58369.

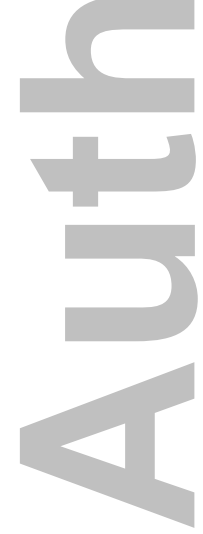


In patients with acute liver failure (ALF), elevated prothrombin time and thrombocytopenia can fuel a perception of a bleeding tendency. However, the incidence, site, risk factors, and clinical significance of bleeding complications have not been previously quantified in a large cohort of patients with ALF. We studied 1770 adult patients enrolled in the ALF Study Group Registry between 1998 and 2016. Bleeding complications and blood component transfusions were collected for 7 days after admission. The relationship of bleeding complications to 21-day mortality was assessed. Despite a median INR of 2.7 and platelet count of $96 \times 10^{9} / \mathrm{L}$ on admission, bleeding complications were observed in only 187 patients (11\%), including 173 spontaneous and 22 post-procedural bleeding episodes. Eighty-four percent of spontaneous bleeding episodes were from an upper gastrointestinal source and rarely resulted in red blood cell (RBC) transfusion. Twenty patients experienced an intracranial bleed, half of which occurred spontaneously and half after intracranial pressure (ICP) monitor placement, and was the proximate cause of death in $20 \%$ and $50 \%$, respectively. Bleeders and patients who received RBC transfusions were more acutely ill from extra-hepatic organ system failure, but not from hepatocellular failure. Consistent with this observation, bleeding complications were associated with lower platelet counts, but not higher INR. Transfusion of any blood component was associated with nearly 2-fold increased death or need for liver transplantation at day 21 , but bleeding complications were the proximate cause of death in only $5 \%$ of cases. Conclusions. Despite a perceived bleeding diathesis, clinically significant bleeding is uncommon in patients with ALF. Bleeding complications in patients with ALF are markers of severe systemic inflammation rather than of coagulopathy and so, portend a poor prognosis. 
Abnormal hemostasis is integral to the definition of acute liver failure (ALF), and is characterized by an elevated International Normalized Ratio (INR) of the prothrombin time (1). Recent studies have suggested that, despite the frequently intimidating elevation of the INR and moderate thrombocytopenia, global hemostasis in most patients with ALF remains normal or "rebalanced," at least in vitro $(2,3)$. Compensatory mechanisms have been identified for each phase of hemostasis in patients with ALF such that pro-hemostatic drivers may actually overcompensate for deficient liver-derived coagulation factors, and result in a relative hypercoagulable state (4).

Whether in vitro rebalance equates with clinical rebalance and a low risk of bleeding complications in patients with ALF has not been determined. Early clinical series suggested that patients with ALF had a propensity to bleed, and that bleeding episodes resulted in increased morbidity and mortality (5-7). Capillary-type bleeding from mucosal erosions of the upper gastrointestinal (UGI) tract were most frequently identified as the source of bleeding, but other mucosal sites included the nasopharynx, lung, and female genitourinary tract (7). Curiously, there has been scant mention of the bleeding incidence or its contribution to the morbidity and mortality of patients with ALF in recent series, leading to a perception that bleeding complications are not an important determinant of outcome. For example, in one of the largest series of ALF patients ever reported (over 2000 cases), bleeding was not mentioned as a complication of ALF or a co-factor in poor outcome (8). The absence of a contemporary update on the incidence and significance of bleeding complications, and the recent laboratory evidence of rebalanced hemostasis may have contributed to the recommendation that "no routine correction of coagulation abnormalities" is warranted in patients with ALF (9). 
Routine assays of hemostasis performed in vitro may not reflect hemostasis in vivo accurately; all coagulation assays are deficient in certain components of the hemostatic system, for example, endothelial factors (10), anti-coagulant pathways and activated platelets. Nevertheless, clinicians continue to rely on the INR to assess bleeding risk, either from spontaneous bleeding or after an invasive procedure. In the present study, we have sought to reanalyze the risk of bleeding in patients with ALF enrolled in the US ALF Study Group Registry. The Registry has prospectively collected clinical and laboratory data on more than 2800 patients with ALF since 1998, including bleeding complications and transfusions of blood components early after admission. In the following work, we have quantified the incidence of spontaneous and post-procedural bleeding complications, estimated the severity of bleeding, explored the indications for blood component transfusion, and associated bleeding complications and receipt of transfusions to 21-day outcome of patients with ALF.

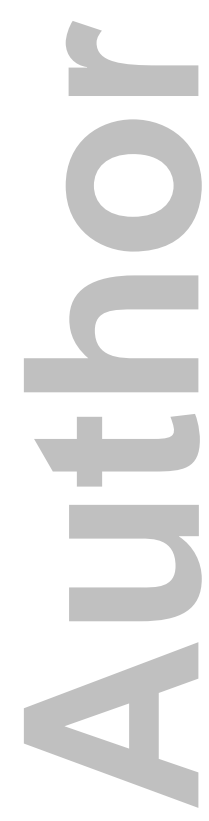




\section{Methods.}

Patients. Study patients were recently described (11), and accrual in the present study followed the algorithm in Supplemental Figure 1. ALF was defined by standard criteria reported by the ALF Study Group previously (12). All patients with ALF in the ALF Study Group Registry enrolled between January 1, 1998 and January 1, 2016 were eligible for inclusion. Of the 2345 patients who were screened, 575 (24\%) were excluded for missing data. The 21 day outcome of the remaining 1770 patients who met entry criteria included $781(44 \%)$ who recovered without liver transplantation (spontaneous survivors; SSs), 430 (24\%) who underwent liver transplantation (LT), and 559 (32\%) who died.

As the percent of excluded patients due to missing data was significant, we performed a comparison of included and excluded Registry enrollees (Supplemental Table 1). Excluded patients appear to have been less acutely ill than included patients, and the missing data suggest that they were less intensively followed. Specifically, excluded patients were less likely to have the systemic inflammatory response syndrome (SIRS), less likely to have high grade hepatic encephalopathy, and had higher platelet counts and lower INRs on admission, than included patients. Excluded patients were also slightly less likely to have had a bleeding complication after study admission ( $7.4 \%$ vs. $10.6 \%$ ), were less likely to receive a blood component transfusion during admission, and less likely to have died at 21 days than included patients. However, bleeding complications as the cause of death were similar in the two groups.

Definitions and Data Collection. Bleeding complications were reported daily by the study site clinical investigators from admission (day 1) through day 7. No formal definition of bleeding was specified in the Registry's Manual of Operations, although sites were required to specify on each day whether bleeding had occurred, and if so, the site of origin. Bleeding was recorded as 
"gastrointestinal," or "other," where the other site of bleeding was required to be entered manually. The case report forms for all bleeders was reviewed by the study principal investigator (RTS) and classified as either spontaneous (non-procedure-related) or post-procedural, and further classified according to the site of bleeding. The adjudication process was deliberately designed to be overly-inclusive without regard to the severity of bleeding or whether the bleeding episode resulted in red blood cell (RBC) transfusion. Additional bleeders were identified through review of case report forms where subjects were identified as having a hemorrhage on imaging studies, as an ICP complication, or as the cause of death. Case report forms of all patients in whom the site clinical investigator indicated that a bleeding complication contributed to a patient's death by day 21 were reviewed in order to adjudicate the role of bleeding in the death, and to classify the bleeding as spontaneous or post-procedural. Daily recording of the following was also required: transfusion of blood products (RBCs, platelets, and plasma); administration of vitamin K, recombinant activated Factor VII (rFVIIa), gastric acid suppression, vasopressors, and $N$-acetylcysteine (NAC); and management decisions including hemodialysis, renal replacement therapy (RRT), mechanical ventilation, liver biopsy, and intracranial pressure (ICP) monitoring. Subjects were not considered bleeders if the episode occurred during or after liver transplantation.

Statistical Analysis. SAS software (version 9.4; Cary, NC) was used to perform statistical analyses. Baseline variables were described using counts and percentages for categorical data, or means and standard deviations (medians and interquartile ranges) for continuous normal (skewed) data. For variables identified as clinically relevant, statistical tests were performed using Chi-square, ANOVA, or Kruskal-Wallis tests. Modeling of hemoglobin, platelet, and INR values over time was performed using a linear mixed model with unstructured covariance for 
each patient to account for the within-patient correlation across measurement days, where bleeding was defined as a dichotomous indicator of bleeding at any time between admission and day 7, LT, discharge, or death. Figures illustrate mean hemoglobin, platelet, and INR estimates for each observation day adjusted for the correlation across measurement days (ie., least square means). Hazard of LT or death are shown as Kaplan-Meier curve with log-rank test statistic. All statistical tests are reported as two-sided with a type I error rate of $5 \%$.
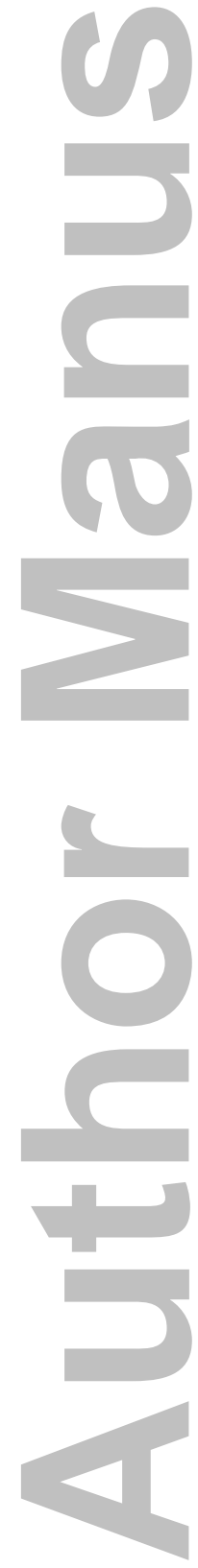


\section{Results. \\ Incidence and clinical characteristics of bleeding complications.}

A total of 1770 adults with ALF entered the study, of whom 430 (24\%) underwent LT and $559(32 \%)$ died by day 21 . Two hundred thirty-seven patients (13\%) underwent ICP monitor placement, the procedure with highest potential morbidity and mortality from bleeding complications. One hundred ninety-five bleeding complications occurred in 187 patients with ALF (Table 1), for an overall incidence of $10.6 \%$ during the first 7 days of admission; 8 patients experienced more than one bleeding complication. Of all bleeding episodes, 173 were spontaneous $(89 \%)$ and 22 were post-procedural $(11 \%)$. The vast majority of spontaneous bleeding complications were from an upper gastrointestinal (UGI) source (163 of 173 complications; 94\%), with 10 additional spontaneous bleeds occurring at an intracranial site either before placement, or in the absence, of an ICP monitor. Post-procedural bleeding from venous access sites were recorded in 8 cases, a nasopharyngeal source after naso-gastric tube placement in 2 cases, genitourinary source after urinary bladder catheterization in 2 cases, and after intracranial pressure (ICP) monitor placement in 10 cases, 5 of which resulted in death. In patients with a recorded primary cause of death (484/599), bleeding complications (spontaneous or post-procedural) were deemed the proximate cause of death in 10 patients $(2.1 \%)$, 7 of whom had spontaneous or post-ICP monitor intracranial bleeding. An additional 6 patients who died between 8-21 days also had bleeding listed as a cause of death (3.3\%). Bleeding episodes most frequently occurred on a single day after admission to the study site (58\%) or resolved within two days (22\%), and most commonly occurred on day 1 (52\%; data not shown).

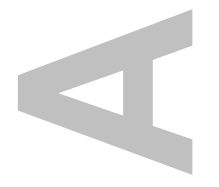




\section{Comparison of patients with and without bleeding complications.}

Clinical features of bleeders and non-bleeders are compared in Table 2. Bleeders were more often male than non-bleeders (40 vs. 30\%, respectively; $\mathrm{P}=0.006$ ), but were otherwise demographically similar. Bleeding complications occurred as frequently in patients with acetaminophen (APAP)-induced as non-APAP-induced etiology. The time delay of presentation for medical care (onset of ALF symptoms to study enrollment) was similar between the two groups ( 5 vs. 6 days in bleeders and non-bleeders, respectively; $\mathrm{P}=0.10$ ). Although bleeding episodes prior to transfer to the study site were not recorded, bleeders were more likely to have received plasma transfusion prior to study admission (65 vs. $42 \%$, respectively; $\mathrm{P}<0.001$ ), and more likely to have been taking aspirin on admission ( 9 vs. $5 \%$, respectively; $\mathrm{P}=0.045$ ), than non-bleeders. However, there was no difference in the proportion of patients on anticoagulants at the time of study admission in the two groups.

Bleeders were generally more systemically ill than non-bleeders and had more extrahepatic organ dysfunction (Table 2). Although the prevalence of the SIRS defined as $\geq 2$ positive components was only modestly higher in bleeders than non-bleeders (80 vs. 74\%, respectively; $\mathrm{P}=0.127$ ), individual components of the SIRS reflected a greater severity of systemic inflammation in bleeders, including the two-sided temperature $\left(<36\right.$ or $>38^{\circ} \mathrm{C} ; 37$ vs. $28 \%$, $\mathrm{P}=0.014)$ and WBC criteria $\left(<4\right.$ or $>12 \times 10^{9} / \mathrm{L} ; 53$ vs. $\left.46 \%, \mathrm{P}=0.052\right)$, pulse $(\mathrm{P}<0.001)$, and $\mathrm{PCO}_{2}$ $(\mathrm{P}=0.028)$, with a trend toward higher respiratory rate in bleeders $(\mathrm{P}=0.09)$. Bleeders more frequently developed high-grade (grade 3 or 4 ) hepatic encephalopathy (62 vs. $48 \%$ on admission, and 86 vs. $63 \%$ over days 1-7), had higher serum creatinine (2.2 \pm 2.3 vs. $1.6 \pm 2.1 \mathrm{mg} / \mathrm{dl})$, higher lactate $(5.4 \pm 8.2$ vs. $4.4 \pm 6.0 \mathrm{mg} / \mathrm{dl})$, lower bicarbonate $(20.0 \pm 10.0$ vs. $22.0 \pm 8.0 \mathrm{mg} / \mathrm{dl})$, and higher phosphate $(3.8 \pm 2.9$ vs. $3.1 \pm 2.3 \mathrm{mg} / \mathrm{dl})$ than non-bleeders $(\mathrm{P}<0.001$, 
except for lactate and bicarbonate, $\mathrm{P}=0.002$ ). Although abnormal laboratory parameters of extrahepatic organ dysfunction were more severe in bleeders, bleeders and non-bleeders had similar degrees of liver dysfunction as assessed by INR, bilirubin, ammonia, and albumin, which were not statistically different between the two groups.

Baseline hemoglobin on admission to the study in bleeders was lower than in nonbleeders $(10.3 \pm 2.8$ vs. $11.1 \pm 3.1 \mathrm{~g} / \mathrm{dl}$, respectively; $\mathrm{P}<0.001)$; nadir hemoglobin over the first 7 days of admission was also lower in bleeders than non-bleeders (8.4 \pm 2.1 vs. 9.2 $\pm 2.5 \mathrm{~g} / \mathrm{dl}$; $\mathrm{P}<0.001)$. However, the mean percent decrease in hemoglobin from admission to nadir in bleeders and non-bleeders was similar (decrease of 15 and 14\%, respectively), and the hemoglobin concentration was similar between the groups on each day after day 2 (Figure 1A).

Although both the admission and the nadir platelet count were lower in bleeders $(96 \pm 92$ and $\left.53 \pm 45 \times 10^{9} / \mathrm{L}\right)$ than non-bleeders $\left(128 \pm 108\right.$ and $77 \pm 81 \times 10^{9} / \mathrm{L}$, respectively; both $\left.\mathrm{P}<0.001\right)$, the admission and peak INR in bleeders $(2.7 \pm 2.4$ and $3.2 \pm 3.3)$ was not significantly different than non-bleeders $(2.8 \pm 2.2$ and $3.3 \pm 2.7$, respectively). In fact, bleeders had significantly lower platelet counts than non-bleeders on each study day $(\mathrm{P}<0.001$ for each day; Figure 2A), while INR was similar between the groups on each day (Figure 2B). There was no relationship of the platelet count to the INR on admission in bleeders or non-bleeders $\left(r^{2}=0.03\right.$ and 0.01 , respectively; data not shown).

Bleeders also received many more therapeutic interventions than non-bleeders, reflecting the severity of their systemic illness (Table 2). The incidence of ICP monitor placement (20 vs. 14\%), RRT (57 vs. 34\%), vasopressor administration (65 vs. 34\%), use of gastric acid suppressants (87 vs. 80\%), and transfusion of plasma (64 vs. 34\%), and platelets (78 vs. 54\%) was higher in bleeders than non-bleeders, respectively (all $\mathrm{P}<0.001$ except for ICP monitor 
placement and gastric acid suppressants, $\mathrm{P}=0.019$ and $\mathrm{P}=0.039$, respectively). Interestingly, transfusion of RBC in bleeders was not different than in non-bleeders (16 vs. 17\%, respectively), again suggesting that the magnitude of the bleeding complication was small. The administration of $N$-acetylcysteine (NAC), which theoretically might increase bleeding episodes by decreasing vonWillebrand Factor multimer size(13), was not associated with bleeding complications.

Comparison of patients who received and did not receive red blood cell transfusions.

The clinical characteristics of patients who received RBC transfusions differed from those of bleeders in several regards. As shown in Table 3, many more patients received RBC transfusions $(651 / 1770 ; 37 \%)$ than experienced bleeding complications $(187 / 1770 ; 11 \%)$; of the 651 patients who received RBC transfusions, only 120 (18\%) experienced bleeding complications. However, bleeding complications were significantly more common in patients who received $\mathrm{RBC}$ transfusions than in those who did not $(18$ vs. 6\%, respectively; $\mathrm{P}<0.001)$. Although a greater proportion of bleeders than non-bleeders were men, a greater proportion of those who received RBC transfusions than those who did not were women (73 vs. 67\%, respectively; $\mathrm{P}=0.003$ ), possibly due to the fact that females entered the study with a lower mean hemoglobin than did men (10.7 vs. $11.9 \mathrm{~g} / \mathrm{dl}$, data not shown). In addition, comparison of serum hemoglobin concentrations in RBC-transfused and non-transfused patients (Figure 1B) suggests that the former were transfused for anemia on admission rather than an acute drop in hemoglobin after admission. Indeed, the mean decrease in hemoglobin from admission to nadir in RBCtransfused and non-transfused patients was similar (15\% and 13\%, respectively), and the difference in hemoglobin in transfused and non-transfused patients (Figure 1B) was greater than 
the difference between bleeders and non-bleeders (Figure 1A), both suggesting that the indication for transfusion was anemia rather than bleeding.

Otherwise, patients who received RBC transfusions resembled bleeders (Table 3): they were more acutely ill than those who were not transfused, more frequently met SIRS criteria $(\mathrm{P}=0.002)$, had a higher proportion of patients reaching high-grade (3 or 4$)$ encephalopathy $(\mathrm{P}<0.001)$, had laboratory parameters reflecting more severe systemic illness, and they received more therapeutic interventions than those who did not receive $\mathrm{RBC}$ transfusions. Also similar to bleeders, receiving RBC transfusions had no consistent relationship to the severity of liver injury by INR, but was significantly related to the platelet count, a marker of systemic inflammation.

\section{Relationship of blood component transfusion to bleeding complications.}

Although patients who experienced bleeding complications were more likely to receive transfusion of platelets and/or plasma than non-bleeders (Table 2), the majority of blood components transfused did not appear to be in response to bleeding complications. As shown in Table 4, 37\%, 56\%, and 26\% of study patients received RBC, plasma, and platelets, respectively, over the course of the first 7 days of admission. However, most patients who received $\mathrm{RBC}$, plasma, or platelets were non-bleeders $(82 \%, 85 \%$, and $81 \%$, respectively). In addition, 5-6\% of patients transfused received blood components before the occurrence of their bleeding complication, indicating that bleeding was not the indication for the transfusion. Therefore, at a minimum, $87 \%, 91 \%$, and $86 \%$ of patients who received RBC, plasma, and platelets, respectively, were transfused for an indication other than active bleeding (for example, for non-hemorrhagic anemia, or prophylaxis before an invasive procedure). 
The practice of administering blood products (RBC, plasma, and/or platelets) during days 1-7 for any indication has decreased by 2.6\%/year between 1998-2015. Nevertheless, the incidence of bleeding complications has remained stable over the same time frame (mean 10.7 $\pm 3.8 \%$ /year) (Supplementary Figure 2). Since the majority of transfusions were given as prophylaxis, this observation suggests that withholding transfusions has not increased bleeding complications in patients with ALF.

\section{Relationship of blood product transfusion and bleeding complications to outcome of ALF.}

The incidence of bleeding complications according to 21 day outcome in spontaneous survivors, those who underwent LT, and those who died was $7 \%, 5 \%$, and $18 \%$, respectively. The data in Table 5 depict the association of blood product transfusion, vitamin K, and rFVIIa during the first 7 days of admission to outcome at day 21. Patients who received RBC, plasma, or platelet transfusions were each nearly twice as likely to have died or undergone LT at day 21 than non-transfused patients. Of the 944 patients who died or underwent LT, RBC, plasma, or platelets were transfused in 45,70 , and $32 \%$, respectively; of 713 spontaneous survivors, transfusions were recorded in 27, 39, and $16 \%$, respectively (all $\mathrm{P}<0.001$ ). Receipt of any blood product was observed in approximately $70 \%$ of patients who died or underwent LT, but only approximately $30 \%$ of spontaneous survivors (data not shown). Although relatively few patients received rFVIIa $(\mathrm{N}=37)$, most died or underwent LT (76\%), and the prevalence of receiving rFVIIa was over 3 -fold higher in this group compared to spontaneous survivors $(\mathrm{P}=0.022)$. Outcomes were significantly better in patients who received vitamin $\mathrm{K}$ than those who did not, with vitamin K received by $20 \%$ of spontaneous survivors, but by those who died or underwent LT in only $15 \%(\mathrm{P}=0.006)$. 
As a total study population, bleeding complications during the first 7 days of admission were associated with negative outcomes at day 21 , with a transplant-free survival (TFS) rate among bleeders of $28 \%$ (median time to transplant/death 6 (95\% CI 4-7) days), while the TFS rate among non-bleeders was 45\% (median time to transplant/death 12 (95\% CI 9-18) days $(\mathrm{P}<0.001$; data not shown). However, as seen in the Kaplan-Meier curves in Figure 3, the presence of bleeding complications only affected TFS in patients with APAP-induced ALF (TFS $34 \%$ in bleeders vs. $63 \%$ in non-bleeders; $\mathrm{P}<0.001$ ), but not in patients with non-APAP ALF.

\section{Discussion.}

The incidence of bleeding complications in this large, contemporary population with ALF was approximately $11 \%$, the majority of whom had clinically insignificant bleeding. These findings from the ALF Study Group Registry contrast with older historical reports, in which many patients not only bled, but died from the bleed. In an early autopsy series of patients with ALF, Gazzard, et al., (6) reported that $\sim 30 \%$ died of a bleeding complication, $\sim 90 \%$ of whom bled from a gastrointestinal source. Other early series reported the incidence of bleeding complications ranged between $50-70 \%$, with death reported from bleeding in $\geq 30 \%(5,7,14)$. Although the incidence and mortality of bleeding complications has decreased for critically ill patients in general (15), these data support the emerging consensus that patients with ALF are not at major risk of significant bleeding complications despite their dramatically elevated INR.

The International Society of Thrombosis and Haemostasis has defined major bleeding as causing death, occurring in a critical area or organ (including intracranial), and/or the need for $\mathrm{RBC}$ transfusion in the setting of a bleed associated with $\mathrm{a} \geq 2 \mathrm{~g} / \mathrm{dl}$ drop in hemoglobin (16). The preponderance of evidence in the present series suggests that few bleeding complications in 
patients with ALF would be categorized as major or even clinically significant. First, $87 \%$ of RBC-transfused patients received the transfusion for an indication other than a bleeding complication, presumably for anemia (Table 4). Second, the magnitude of decrease in hemoglobin from study admission to nadir within 7 days was nearly identical in patients who experienced bleeding complications and those who did not (decrease of 15 vs. $14 \%$, respectively). Third, in patients who died with a reason for death recorded, only 10 of 1770 patients reviewed were considered to have died as a consequence of a bleeding complication, 7 of whom died of intracranial hemorrhage, and 5 of which were likely related to ICP monitor placement. Finally, differences in mortality between bleeders and non-bleeders were only observed after day 7 (Figure 3), suggesting a temporal dissociation between the bleeding episode and death. The finding that 10 patients had intracranial bleeds in the absence of an ICP monitor, presumably a complication of cerebral edema, has not been previously reported.

Although post-procedural bleeding complications remain a significant concern for clinicians caring for patients with ALF, the data suggest that they are rare. For example, 641 patients underwent central venous catheter placement for RRT, yet there were fewer than 5 instances of bleeding at the insertion site $(0.8 \%)$; no other more serious bleeding complications were reported. The observation appears to support a recent series from an intensive care liver unit, in which 658 central venous cannulations in 283 patients ( 35\% with APAP overdose) with INR $\geq 1.5$ and/or platelet count $\leq 150 \times 10^{9} / \mathrm{L}$ and without routine plasma or platelet transfusion resulted in only 1 serious bleeding complication, a hemothorax (17). Our low incidence of bleeding after RRT catheter insertion may have been influenced by blood product prophylaxis, but the above study in which plasma and platelets were only transfused in 1.8 and $4.2 \%$ of patients, respectively, also raises the question of whether such prophylaxis were necessary in the 
first place. The observation that there has been a steady decline in blood component transfusion over the 17 years of data collection by the ALF Study Group without an increase in bleeding complications (Supplementary Figure 2) also raises this question. Intracranial bleeding after ICP monitor placement, however, remains a significant threat although is uncommon, occurring in 10 of $237(4.2 \%)$ of our study patients, 5 of whom (2\%) probably died of complications of the bleed. These statistics compare favorably with fatal bleeding complication rates of $1 \%, 5 \%$, and $4 \%$ of patients with ALF who received ICP monitors in epidural, subdural, and intraparenchymal locations, respectively (18). These data highlight the fact that placement of an ICP carries a significant risk of intracranial bleeding and death.

Despite their generally mild severity, bleeding complications were associated with lower 21-day TFS (Figure 3), but only for patients with APAP-induced ALF. The occurrence of bleeding complications had no effect on TFS in patients with non-APAP-induced ALF. In other analyses, we have found the occurrence of bleeding complications in patients with APAPinduced ALF to be a marker of particularly severe acute illness (data not shown). As shown in Table 5, the 21-day outcome of LT or death was nearly 2-fold higher in patients who received transfusion of any blood component within the first 7 days of admission. Therefore, it is also conceivable that administering blood components early after admission has adverse effects that are particularly significant for patients with APAP-induced ALF, possibly by exacerbating a preexisting hypercoagulable state, resulting in microvascular thrombosis within the liver and peripheral circulation, and compounding the primary liver injury (19) and poor peripheral tissue perfusion (20), respectively. Other hazards of blood product transfusion, such as volume overload, transfusion-associated lung injury, immune dysregulation, and exacerbation of intracranial hypertension, are also possible. 
The data also suggest that bleeding complications and the development of anemia are primarily due to severe systemic inflammation. In Tables 2 and 3, both bleeders and those receiving $\mathrm{RBC}$ transfusions are characterized by clinical features and laboratories suggestive of more severe systemic injury than non-bleeders and non-transfused patients, respectively. The finding that platelet count was significantly lower in bleeders and RBC-transfused patients is consistent with this hypothesis, since we have recently shown in the same patient population that the decline in platelet count after admission is proportional to the severity of systemic complications and the SIRS (11). The fact that the INR is not different between these populations is also consistent with our previous observations that INR does not vary with the severity of systemic inflammation. Another interpretation of these data might be that lower platelet count, but not higher INR, is a more important risk factor for bleeding complications, as has been suggested by other authors (6).

For the vast majority of patients with ALF and UGI bleeding, the likely source is "stressrelated mucosal disease" (SRMD), a manifestation of critical illness characterized by intense systemic inflammation (21). In a recent survey of >1000 ICU patients, clinically significant UGI bleeding occurred in only $2.6 \%$, but risk factors included three integral features of the ALF syndrome: liver disease (OR 7.6), coagulopathy (OR 5.2), and RRT (OR 6.9) (15). The responsible lesion, sub-epithelial hemorrhage, is caused by gastric mucosal ischemia proportional to the severity of underlying illness, rather than defective hemostasis (21). Consequently, prophylaxis with acid suppression has not been universally shown to decrease its incidence (22). Although early studies in patients with ALF suggested benefit from histamine-2receptor antagonists (23), our data suggest no apparent benefit from gastric acid inhibition. The 
difference between early and contemporary series may be a recent overall decrease in SRMD as a result of improved ICU care, resulting in decreased mucosal hypoperfusion (22).

There are multiple possible explanations for the low incidence and mild severity of bleeding complications in patients with ALF. Thrombin generation in ALF is generally normal in vitro in the presence of thrombomodulin $(24,25)$. Deficiency of liver-derived procoagulant proteins is proportional to deficiency of anticoagulant proteins (2). VonWillebrand factor and Factor VIII levels are increased dramatically due to endothelial activation/injury from the SIRS $(26,27)$. Procoagulant microparticles are released by systemic inflammation (28). Finally, fibrinolysis is severely impaired such that clot lysis in many patients cannot be detected (24). Another obvious possibility remains unproven: administering prophylactic blood components to treat the high INR and low platelets is effective in decreasing bleeding complications.

We acknowledge limitations in our data and conclusions. The ALF Study Group Registry was not designed to link bleeding complications to specific procedures, blood product transfusions, and episodes of hemodynamic instability, and post-hoc analyses without predefined research questions increase the risk of bias. Missing data led to exclusion of $24 \%$ of Registry participants with the consequences noted in Supplemental Table 1: the apparent exclusion of less acutely ill patients from the analysis. We emphasize, however, that we aimed to describe a "worst case scenario" in order not to underemphasize the risks of bleeding in patients with ALF, and the exclusion of these patients should, therefore, not have contributed to an underestimate of the risk. Although an earlier version of the Registry Operations Protocol Manual required quantitation of administered blood products, a later version has not. The clinical indication for transfusion of a specific blood product was also not captured. Therefore, some of our conclusions were admittedly reached on circumstantial evidence. 
In conclusion, bleeding complications in patients with ALF are primarily clinically insignificant. Spontaneous bleeding complications are comprised overwhelmingly of self-limited UGI bleeding, which appears to have decreased in incidence and severity over the last 40 years. Post-procedural complications remain rare, and those linked to the death of patients with ALF were universally complications of ICP monitor placement. Transfusion of blood components is associated with increased 21-day poor outcome (LT and/or death). Future study must answer an important question raised by this report: does pro-hemostatic blood component transfusion decrease bleeding complications or adversely affect patients with ALF?
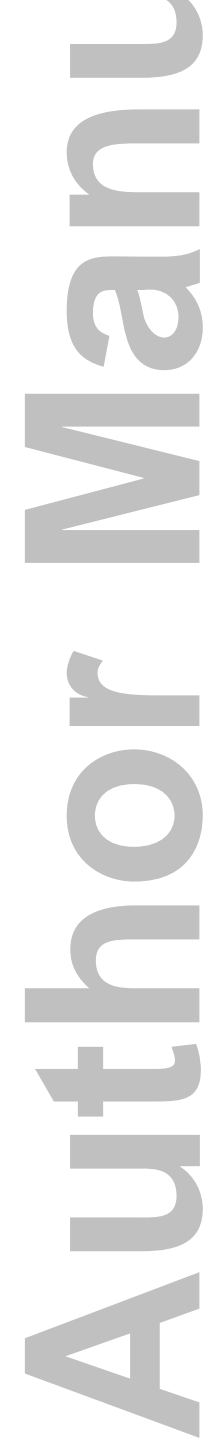


\section{References.}

1. Trey C, Davidson CS. The management of fulminant hepatic failure. Prog Liver Dis 1970;3:282-298.

2. Stravitz RT, Lisman T, Luketic VA, Sterling RK, Puri P, Fuchs M, et al. Minimal effects of acute liver injury/acute liver failure on hemostasis as assessed by thromboelastography. J Hepatol 2012;56:129-136.

3. Agarwal B, Wright G, Gatt A, Riddell A, Vemala V, Mallett S, et al. Evaluation of coagulation abnormalities in acute liver failure. J Hepatol 2012;57:780-786.

4. Lisman T, Stravitz RT. Rebalanced Hemostasis in Patients with Acute Liver Failure. Semin Thromb Hemost 2015;41:468-473.

5. Ritt DJ, Whelan G, Werner DJ, Eigenbrodt EH, Schenker S, Combes B. Acute hepatic necrosis with stupor or coma. An analysis of thirty-one patients. Medicine (Baltimore) 1969;48:151-172.

6. Gazzard BG, Portmann B, Murray-Lyon IM, Williams R. Causes of death in fulminant hepatic failure and relationship to quantitative histological assessment of parenchymal damage. Q J Med 1975;44:615-626.

7. Tandon BN, Joshi YK, Tandon M. Acute liver failure. Experience with 145 patients. J Clin Gastroenterol 1986;8:664-668.

8. Bernal W, Hyyrylainen A, Gera A, Audimoolam VK, McPhail MJ, Auzinger G, et al. Lessons from look-back in acute liver failure? A single centre experience of 3300 patients. J Hepatol 2013;59:74-80.

9. Bernal W, Wendon J. Acute liver failure. N Engl J Med 2013;369:2525-2534.

10. Tripodi A, Salerno F, Chantarangkul V, Clerici M, Cazzaniga M, Primignani M, et al. Evidence of normal thrombin generation in cirrhosis despite abnormal conventional coagulation tests. Hepatology 2005;41:553-558.

11. Stravitz RT, Ellerbe C, Durkalski V, Reuben A, Lisman T, Lee WM. Thrombocytopenia Is Associated With Multi-organ System Failure in Patients With Acute Liver Failure. Clin Gastroenterol Hepatol 2016;14:613-620.

12. Reuben A, Tillman H, Fontana RJ, Davern T, McGuire B, Stravitz RT, et al. Outcomes in Adults With Acute Liver Failure Between 1998 and 2013: An Observational Cohort Study. Ann Intern Med 2016 Apr 5.

13. Chen J, Reheman A, Gushiken FC, Nolasco L, Fu X, Moake JL, et al. N-acetylcysteine reduces the size and activity of von Willebrand factor in human plasma and mice. J Clin Invest 2011;121:593-603. 
14. Saunders SJ, Hickman R, Macdonald R, Terblanche J. The treatment of acute liver failure. Prog Liver Dis 1972;4:333-344.

15. Krag M, Perner A, Wetterslev J, Wise MP, Borthwick M, Bendel S, et al. Prevalence and outcome of gastrointestinal bleeding and use of acid suppressants in acutely ill adult intensive care patients. Intensive Care Med 2015;41:833-845.

16. Schulman S, Kearon C. Definition of major bleeding in clinical investigations of antihemostatic medicinal products in non-surgical patients. J Thromb Haemost 2005;3:692-694.

17. Fisher NC, Mutimer DJ. Central venous cannulation in patients with liver disease and coagulopathy--a prospective audit. Intensive Care Med 1999;25:481-485.

18. Blei AT, Olafsson S, Webster S, Levy R. Complications of intracranial pressure monitoring in fulminant hepatic failure. Lancet 1993;341:157-158.

19. Ganey PE, Luyendyk JP, Newport SW, Eagle TM, Maddox JF, Mackman N, et al. Role of the coagulation system in acetaminophen-induced hepatotoxicity in mice. Hepatology 2007;46:1177-1186.

20. Harrison PM, Wendon JA, Gimson AE, Alexander GJ, Williams R. Improvement by acetylcysteine of hemodynamics and oxygen transport in fulminant hepatic failure. $\mathrm{N}$ Engl J Med 1991;324:1852-1857.

21. Laine L, Takeuchi K, Tarnawski A. Gastric mucosal defense and cytoprotection: bench to bedside. Gastroenterology 2008;135:41-60.

22. Faisy C, Guerot E, Diehl JL, Iftimovici E, Fagon JY. Clinically significant gastrointestinal bleeding in critically ill patients with and without stress-ulcer prophylaxis. Intensive Care Med 2003;29:1306-1313.

23. Macdougall BR, Bailey RJ, Williams R. H2-receptor antagonists and antacids in the prevention of acute gastrointestinal haemorrhage in fulminant hepatic failure. Two controlled trials. Lancet 1977;1:617-619.

24. Lisman T, Bakhtiari K, Adelmeijer J, Meijers JC, Porte RJ, Stravitz RT. Intact thrombin generation and decreased fibrinolytic capacity in patients with acute liver injury or acute liver failure. J Thromb Haemost 2012;10:1312-1319.

25. Habib M, Roberts LN, Patel RK, Wendon J, Bernal W, Arya R. Evidence of rebalanced coagulation in acute liver injury and acute liver failure as measured by thrombin generation. Liver Int 2014;34:672-678.

26. Hugenholtz GC, Adelmeijer J, Meijers JC, Porte RJ, Stravitz RT, Lisman T. An unbalance between von Willebrand factor and ADAMTS13 in acute liver failure: implications for hemostasis and clinical outcome. Hepatology 2013;58:752-761. 
27. Agarwal B, Gatt A, Riddell A, Wright G, Chowdary P, Jalan R, et al. Hemostasis in patients with acute kidney injury secondary to acute liver failure. Kidney Int 2013;84:158-163.

28. Stravitz RT, Bowling R, Bradford RL, Key NS, Glover S, Thacker LR, et al. Role of procoagulant microparticles in mediating complications and outcome of acute liver injury/acute liver failure. Hepatology 2013;58:304-313.
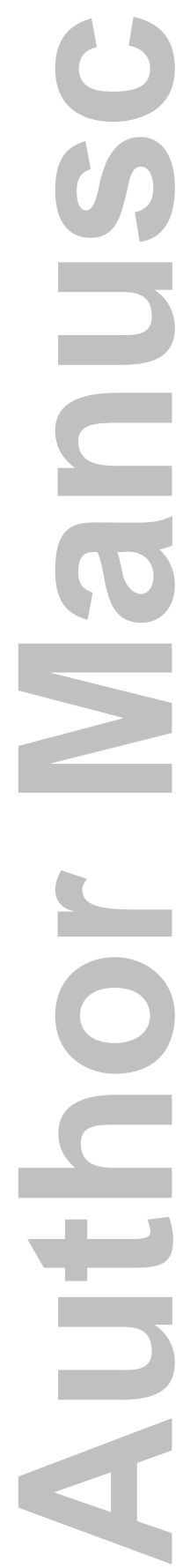
Acknowledgements. With great appreciation, we would like to acknowledge the support of our NIDDK Project Officers, Drs. Edward Doo and Averell Sherker.

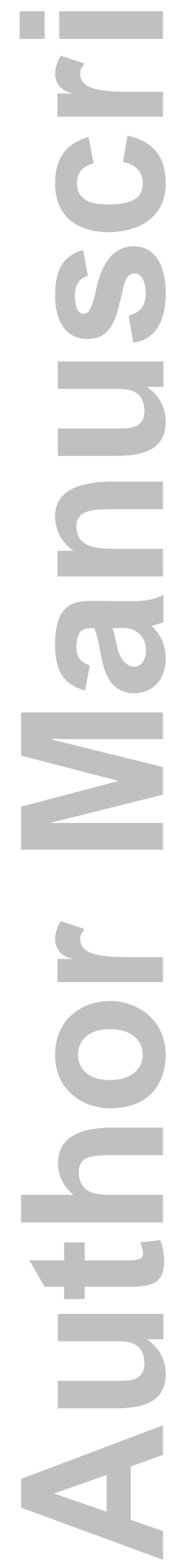




\section{Figure Legends.}

Figure 1. Blood hemoglobin concentration (g/dl) on each day after admission for ALF. (A).

Hemoglobin according to study day in early bleeders vs. non-bleeders. (B). Hemoglobin according to study day in patients who received red blood cell (RBC) transfusions vs. those who did not. $* \mathrm{P}<0.05, * * \mathrm{P}<0.01, * * * \mathrm{P}<0.001$

Figure 2. INR (A) and platelet count (B) of patients on days 1-7 after admission to the study according to the occurrence of bleeding complications. $* * * \mathrm{P}<0.001$.

Figure 3. Kaplan-Meier curve of transplant-free survival (TFS) according to the occurrence of bleeding complications between days 1-7 in patients with acetaminophen (APAP)- and non-APAPinduced ALF. Overall, the TFS among non-bleeders was $45.2 \%$, with median time to transplant/death occurring at 12 (95\% CI 9-18) days, and TFS among bleeders was $27.6 \%$, with median time to transplant/death occurring at $6(95 \% \mathrm{CI} 4-7)$ days $(\mathrm{P}<0.001)$. According to etiology, this difference is due to a difference in patients with APAP-induced ALF $(\mathrm{P}<0.001)$; there was no significant difference in TFS in patients with non-APAP-induced ALF according to the occurrence of bleeding complications.

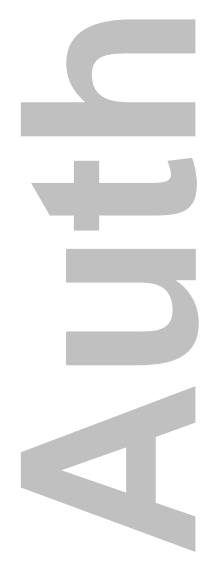




\begin{tabular}{|c|l|c|c|}
\hline \multirow{2}{*}{$\begin{array}{c}\text { Cause of } \\
\text { Bleeding }\end{array}$} & \multicolumn{1}{|c|}{ Bleeding Site } & $\begin{array}{c}\text { Total } \\
\text { Occurrences* } \\
(\mathbf{N})\end{array}$ & $\begin{array}{c}\text { Cause of } \\
\text { Death } \\
\text { (N) }\end{array}$ \\
\hline \multirow{2}{*}{ Spontaneous } & UGI & 163 & 3 \\
\cline { 2 - 4 } & Intracranial & 10 & 2 \\
\hline \multirow{3}{*}{ Post-Procedural } & Venous access site & 8 & 0 \\
\cline { 2 - 4 } & Intracranial (ICP monitor) & 10 & 5 \\
\cline { 2 - 4 } & Nasopharyngeal & 2 & 0 \\
\cline { 2 - 4 } & Genitourinary & 2 & 10 \\
\hline Total & & & \\
\hline
\end{tabular}

Table 1. Sites and causes of bleeding complications in patients with ALF.

*N=2 had both spontaneous UGI and spontaneous intracranial bleeding $\mathrm{N}=2$ had both spontaneous UGI and post-procedural intracranial bleeding

$\mathrm{N}=4$ had both spontaneous UGI and post-procedural bleeding at venous access site

ICP, intracranial pressure; UGI, upper gastrointestinal 


\begin{tabular}{|c|c|c|c|c|}
\hline Clinical Feature & $\mathbf{N}$ & $\begin{array}{c}\text { Non-Bleeders } \\
(\mathbf{N}=\mathbf{1 , 5 8 3}) \\
\mathbf{N} \pm \mathrm{SD}(\%)\end{array}$ & $\begin{array}{c}\text { Bleeders } \\
(\mathrm{N}=187) \\
\mathrm{N} \pm \mathrm{SD}(\%)\end{array}$ & $\mathbf{P}$ \\
\hline \multicolumn{5}{|l|}{ Demographics } \\
\hline Age (Years) & 1770 & $41 \pm 15$ & $42 \pm 14$ & 0.499 \\
\hline Gender (\% Female) & 1770 & 1109(70.1) & $112(59.9)$ & 0.006 \\
\hline Race (\% Caucasian $)$ & 1770 & 1164(73.5) & $145(77.5)$ & 0.274 \\
\hline APAP Etiology of ALF & 1770 & $710(44.9)$ & $88(47.1)$ & 0.62 \\
\hline \multicolumn{5}{|l|}{ Clinical Features on Admission } \\
\hline Symptoms to enrollment (d) & 1719 & $6 \pm 13$ & $5 \pm 11$ & 0.100 \\
\hline Plasma before admission & 1720 & $644(41.9)$ & $118(64.8)$ & $<0.001$ \\
\hline Anticoagulants & 1770 & $41(2.6)$ & $5(2.7)$ & --- \\
\hline Aspirin & 1770 & $83(5.2)$ & $17(9.1)$ & 0.047 \\
\hline SIRS ( $\% \geq 2$ components) & 1364 & $894(74.4)$ & $130(80.2)$ & 0.127 \\
\hline SIRS-Temperature $\left(\mathrm{N}<36\right.$ or $\left.>38^{\circ} \mathrm{C}\right)$ & 1710 & $425(28)$ & $66(37)$ & 0.014 \\
\hline SIRS-Pulse (beats/min) & 1757 & $97 \pm 29$ & $105 \pm 32$ & $<0.001$ \\
\hline SIRS-Respiratory rate (breaths/min) & 1721 & $19 \pm 8$ & $20 \pm 10$ & 0.09 \\
\hline SIRS-PCO $2(\mathrm{mmHg})$ & 1335 & $31 \pm 10$ & $30 \pm 10$ & 0.028 \\
\hline SIRS-WBC $\left(\mathrm{N}<4\right.$ or $\left.>12 \times 10^{9} / \mathrm{L}\right)$ & 1770 & $723(46)$ & $100(53)$ & 0.052 \\
\hline Ammonia $(\mu \mathrm{M})$ & 1032 & $99.0 \pm 95.0$ & $93.0 \pm 79.5$ & 0.244 \\
\hline Encephalopathy Grade 3/4 & 1721 & $733(47.8)$ & $115(61.5)$ & $<0.001$ \\
\hline Creatinine $(\mathrm{mg} / \mathrm{dl})$ & 1766 & $1.6 \pm 2.1$ & $2.2 \pm 2.3$ & $<0.001$ \\
\hline INR & 1770 & $2.8 \pm 2.2$ & $2.7 \pm 2.4$ & 0.895 \\
\hline Total bilirubin (mg/dl) & 1752 & $7.6 \pm 16.4$ & $6.8 \pm 13.1$ & 0.226 \\
\hline Albumin $(\mathrm{g} / \mathrm{dl})$ & 1616 & $2.7 \pm 0.8$ & $2.7 \pm 0.6$ & 0.549 \\
\hline Lactate $(\mathrm{mg} / \mathrm{dl})$ & 971 & $4.4 \pm 6.0$ & $5.4 \pm 8.2$ & 0.002 \\
\hline Bicarbonate (mg/dl) & 1481 & $22.0 \pm 8.0$ & $20.0 \pm 10.0$ & 0.002 \\
\hline Phosphate $(\mathrm{mg} / \mathrm{dl})$ & 1539 & $3.1 \pm 2.3$ & $3.8 \pm 2.9$ & $<0.001$ \\
\hline Platelet count $\left(\times 10^{9} / \mathrm{L}\right)$ & 1770 & $128 \pm 108$ & $96 \pm 92$ & $<0.001$ \\
\hline $\mathrm{WBC}\left(\times 10^{9} / \mathrm{L}\right)$ & 1770 & $10.1 \pm 8.1$ & $10.6 \pm 9.7$ & 0.239 \\
\hline Hemoglobin $(\mathrm{g} / \mathrm{dl})$ & 1764 & $11.1 \pm 3.1$ & $10.3 \pm 2.8$ & $<0.001$ \\
\hline \multicolumn{5}{|c|}{ Clinical Features after Admission, Days 1-7 } \\
\hline INR peak & 1770 & $3.3 \pm 2.7$ & $3.2 \pm 3.3$ & 0.22 \\
\hline Platelet count nadir $\left(\times 10^{9} / \mathrm{L}\right)$ & 1770 & $77 \pm 81$ & $53 \pm 45$ & $<0.001$ \\
\hline Hemoglobin nadir $(\mathrm{g} / \mathrm{dl})$ & 1770 & $9.2 \pm 2.5$ & $8.4 \pm 2.1$ & $<0.001$ \\
\hline Encephalopathy Grade 3/4 & 1734 & $981(63.4)$ & $161(86.1)$ & $<0.001$ \\
\hline Infection & 1770 & $155(9.8)$ & $16(8.6)$ & 0.682 \\
\hline \multicolumn{5}{|l|}{ Interventions after Admission, Days 1-7 } \\
\hline ICP Monitor Placement & 1634 & $201(13.8)$ & $36(20.7)$ & 0.019 \\
\hline Renal Replacement Therapy & 1770 & $534(33.7)$ & $107(57.2)$ & $<0.001$ \\
\hline Vasopressors & 1770 & $531(33.5)$ & $121(64.7)$ & $<0.001$ \\
\hline$N$-acetylcysteine & 1770 & $967(61.1)$ & $121(64.7)$ & 0.378 \\
\hline Gastric Acid Suppression & 1770 & $1267(80.0)$ & $162(86.6)$ & 0.039 \\
\hline RBC Transfusion & 1770 & $265(16.7)$ & $30(16.0)$ & 0.89 \\
\hline Plasma Transfusion & 1770 & $531(33.5)$ & $120(64.2)$ & $<0.001$ \\
\hline Platelet Transfusion & 1770 & $849(53.6)$ & $145(77.5)$ & $<0.001$ \\
\hline \multicolumn{5}{|l|}{ Outcomes at Day 21} \\
\hline Transplant-free Survival & 1770 & $723(45.7)$ & $58(31.0)$ & $<0.001$ \\
\hline Liver Transplantation & 1757 & $407(25.9)$ & $23(12.4)$ & $<0.001$ \\
\hline Died after LT & 430 & $39(9.6)$ & $1(4.3)$ & $<0.001$ \\
\hline Died & 1770 & 492(31.1) & $107(57.2)$ & $<0.001$ \\
\hline
\end{tabular}


Table 2. Demographic and clinical features of patients with ALF with and without bleeding complications during days 1-7.

APAP, acetaminophen; LT, liver transplantation; $\mathrm{PCO}_{2}$, partial pressure of carbon dioxide; $\mathrm{RBC}$, red blood cells; SIRS, systemic inflammatory response syndrome (and individual components); $\mathrm{WBC}$, white blood cells.
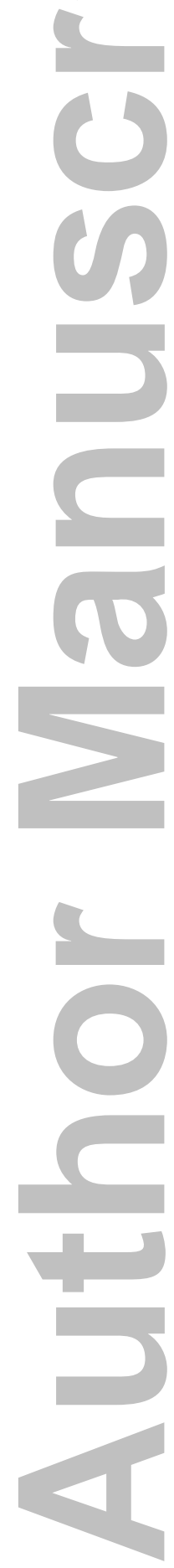


\begin{tabular}{|c|c|c|c|c|}
\hline Clinical Feature & $\mathbf{N}$ & $\begin{array}{c}\text { No } R B C \\
\text { Transfusions } \\
\text { N=1119 } \\
\text { (Mean N, \%) }\end{array}$ & $\begin{array}{c}\text { RBC } \\
\text { Transfusions } \\
\text { N = 651 } \\
\text { (Mean N, \%) }\end{array}$ & $\mathbf{P}$ \\
\hline \multicolumn{5}{|l|}{ Demographics } \\
\hline Age (Years) & 1770 & $42 \pm 15$ & $41 \pm 14$ & 0.15 \\
\hline Gender ( $\%$ Female $)$ & 1770 & $744(66.5)$ & $477(73.3)$ & 0.003 \\
\hline Race (Caucasian) & 1770 & $842(75.2)$ & $467(71.7)$ & 0.117 \\
\hline APAP Etiology of ALF & 1770 & $523(46.7)$ & $275(42.2)$ & 0.075 \\
\hline \multicolumn{5}{|l|}{ Clinical Features on Admission } \\
\hline SIRS $(\% \geq 2)$ & 1364 & $580(72.0)$ & 444(79.4) & 0.002 \\
\hline Ammonia $(\mu \mathrm{M})$ & 1032 & $98.0 \pm 90.0$ & $101.0 \pm 97.0$ & 0.826 \\
\hline Encephalopathy Grade (\% 3/4) & 1721 & 451(41.9) & $397(61.6)$ & $<0.001$ \\
\hline Creatinine $(\mathrm{mg} / \mathrm{dl})$ & 1766 & $1.3 \pm 1.9$ & $2.1 \pm 2.3$ & $<0.001$ \\
\hline INR & 1770 & $2.9 \pm 2.2$ & $2.8 \pm 2.2$ & 0.129 \\
\hline Total bilirubin $(\mathrm{mg} / \mathrm{dl})$ & 1752 & $7.0 \pm 15.6$ & $8.0 \pm 17.0$ & $<0.001$ \\
\hline Albumin $(\mathrm{g} / \mathrm{dl})$ & 1616 & $2.7 \pm 0.7$ & $2.7 \pm 0.8$ & 0.17 \\
\hline Lactate $(\mathrm{mg} / \mathrm{dl})$ & 971 & $3.9 \pm 4.7$ & $5.9 \pm 7.7$ & $<0.001$ \\
\hline Bicarbonate (mg/dl) & 1481 & $22.0 \pm 8.0$ & $20.0 \pm 8.8$ & $<0.001$ \\
\hline Phosphate (mg/dl) & 1539 & $3.0 \pm 2.2$ & $3.4 \pm 2.7$ & $<0.001$ \\
\hline Platelet count $\left(\times 10^{9} / \mathrm{L}\right)$ & 1770 & $133.0 \pm 104.0$ & $108.0 \pm 102.5$ & $<0.001$ \\
\hline $\mathrm{WBC}\left(\times 10^{9} / \mathrm{L}\right)$ & 1770 & $9.6 \pm 7.4$ & $10.9 \pm 9.9$ & $<0.001$ \\
\hline Hemoglobin $(\mathrm{g} / \mathrm{dl})$ & 1764 & $11.5 \pm 2.9$ & $9.9 \pm 2.9$ & $<0.001$ \\
\hline \multicolumn{5}{|c|}{ Clinical Features after Admission, Days 1-7 } \\
\hline INR peak & 1770 & $3.3 \pm 2.7$ & $3.3 \pm 2.8$ & 0.586 \\
\hline Platelet count nadir $\left(\times 10^{9} / \mathrm{L}\right)$ & 1770 & $94.0 \pm 81.0$ & $50.0 \pm 48.0$ & $<0.001$ \\
\hline Hemoglobin nadir $(\mathrm{g} / \mathrm{dl})$ & 1770 & $9.8 \pm 2.5$ & $8.2 \pm 1.6$ & $<0.001$ \\
\hline Encephalopathy Grade $3 / 4$ & 1734 & $613(56.3)$ & $529(82.0)$ & $<0.001$ \\
\hline Infection & 1770 & $125(11.2)$ & $46(7.1)$ & 0.006 \\
\hline Bleeding Complication & 1770 & $67(6.0)$ & $120(18.4)$ & $<0.001$ \\
\hline \multicolumn{5}{|c|}{ Interventions after Admission, Days 1-7 } \\
\hline ICP Monitor Placement & 1634 & 99(9.4) & $138(23.7)$ & $<0.001$ \\
\hline Renal Replacement Therapy & 1770 & $271(24.2)$ & $370(56.8)$ & $<0.001$ \\
\hline Vasopressors & 1770 & $300(26.8)$ & $352(54.1)$ & $<0.001$ \\
\hline$N$-acetylcysteine & 1770 & $722(64.5)$ & $366(56.2)$ & $<0.001$ \\
\hline Gastric Acid Suppression & 1770 & $892(79.7)$ & $537(82.5)$ & 0.172 \\
\hline Plasma Transfusion & 1770 & $210(18.8)$ & $85(13.1)$ & 0.002 \\
\hline Platelet Transfusion & 1770 & $451(40.3)$ & $543(83.4)$ & $<0.001$ \\
\hline
\end{tabular}

Table 3. Clinical characteristics of patients with ALF who received or did not receive red blood cell transfusion during days 1-7. 


\begin{tabular}{|c|c|c|c|c|c|}
\hline \multirow{3}{*}{$\begin{array}{c}\text { Blood } \\
\text { Component }\end{array}$} & \multicolumn{5}{|c|}{ Patients Receiving Blood Component Transfusions N (\%) } \\
\hline & \multirow{2}{*}{$\begin{array}{c}\text { Total } \\
\text { Transfused }\end{array}$} & \multicolumn{2}{|c|}{ Bleeders Transfused } & \multirow{2}{*}{$\begin{array}{c}\text { Non-Bleeders } \\
\text { Transfused }\end{array}$} & \multirow{2}{*}{$\begin{array}{l}\text { Total Transfused for } \\
\text { Non-Bleeding } \\
\text { Indication** }\end{array}$} \\
\hline & & Before Bleeding & At/after Bleeding* & & \\
\hline RBC & $651(37 \%)$ & $34(5.2 \%)$ & $86(13 \%)$ & $531(82 \%)$ & $565(87 \%)$ \\
\hline Plasma & $994(56 \%)$ & $60(6.0 \%)$ & $85(8.6 \%)$ & $849(85 \%)$ & 909 (91\%) \\
\hline Platelets & $435(26 \%)$ & $22(5.1 \%)$ & $60(14 \%)$ & $353(81 \%)$ & $375(86 \%)$ \\
\hline
\end{tabular}

Table 4. Relationship of blood component administration to early bleeding complications. $\mathrm{RBC}$, red blood cells.

*Defined as patients who received blood component transfusion on the same day as, or any day after, bleeding complication.

**Includes non-bleeders who received blood component transfusions and bleeders who received transfusions before their bleeding episodes.

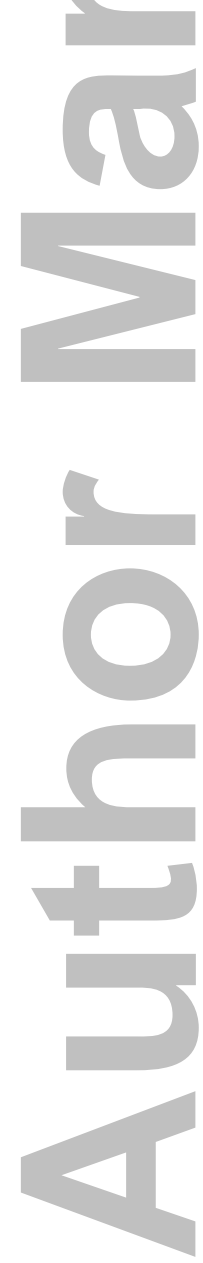




\begin{tabular}{|c|c|c|c|c|c|}
\hline \multirow{3}{*}{$\begin{array}{c}\text { Treatment } \\
\text { During Inpatient } \\
\text { (Day } 1-7 \text { ) }\end{array}$} & \multicolumn{5}{|c|}{ Outcome at Day 21} \\
\hline & \multirow[b]{2}{*}{$\begin{array}{c}\text { Spontaneous } \\
\text { Survivors } \\
(\mathbf{N}=713) \\
\mathbf{N}(\%)\end{array}$} & \multicolumn{3}{|c|}{ Non-Spontaneous Survivors (NSS) } & \multirow[b]{2}{*}{$\mathbf{P}^{*}$} \\
\hline & & $\begin{array}{c}\text { All NSS } \\
(\mathbf{N}=944) \\
\mathbf{N}(\%)\end{array}$ & $\begin{array}{c}\text { Liver } \\
\text { Transplantation } \\
(\mathbf{N}=430) \\
\mathbf{N}(\%)\end{array}$ & $\begin{array}{c}\text { Death } \\
(\mathbf{N}=599) \\
\text { N }(\%)\end{array}$ & \\
\hline Vitamin K & $152(20 \%)$ & $143(15 \%)$ & $54(13 \%)$ & $92(15 \%)$ & 0.006 \\
\hline rVIIa & $9(1.2 \%)$ & $28(2.8 \%)$ & $16(4 \%)$ & $13(2 \%)$ & 0.022 \\
\hline RBC Transfusion & $207(27 \%)$ & $444(45 \%)$ & $197(46 \%)$ & $278(46 \%)$ & $<0.001$ \\
\hline $\begin{array}{l}\text { Plasma } \\
\text { Transfusion }\end{array}$ & $302(39 \%)$ & $692(70 \%)$ & $312(73 \%)$ & $415(69 \%)$ & $<0.001$ \\
\hline $\begin{array}{c}\text { Platelet } \\
\text { Transfusion }\end{array}$ & $122(16 \%)$ & $313(32 \%)$ & $141(33 \%)$ & $192(32 \%)$ & $<0.001$ \\
\hline
\end{tabular}

Table 5. Relationship between transfusion of RBC, plasma, or platelets between days 1-7 to outcome of ALF at day 21. 


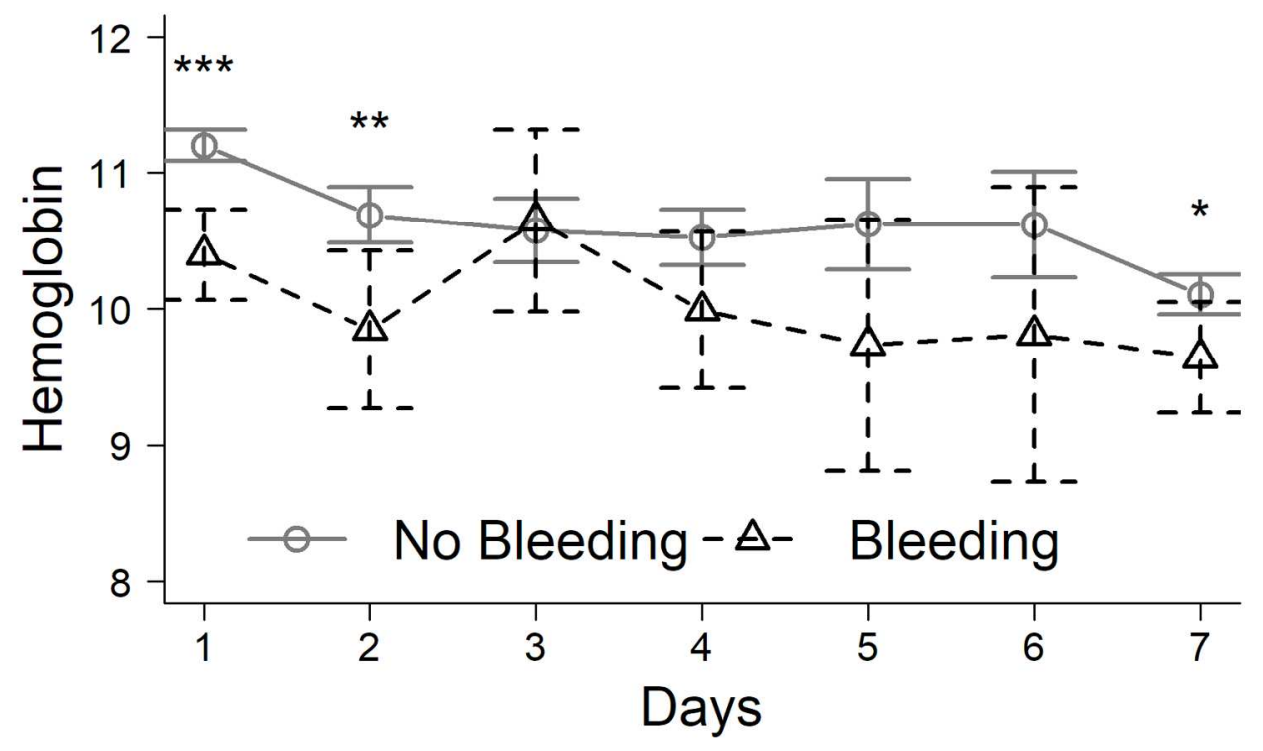

$152 \times 95 \mathrm{~mm}(300 \times 300$ DPI $)$ 


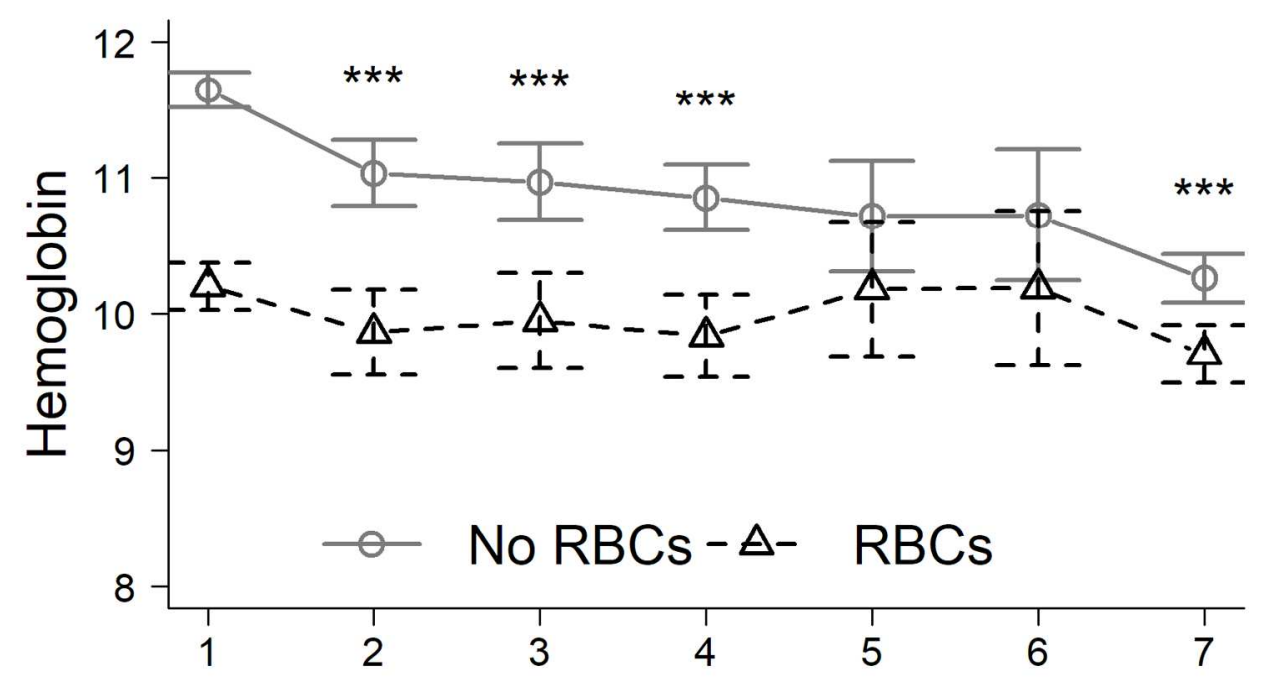

$152 \times 95 \mathrm{~mm}(300 \times 300 \mathrm{DPI})$ 


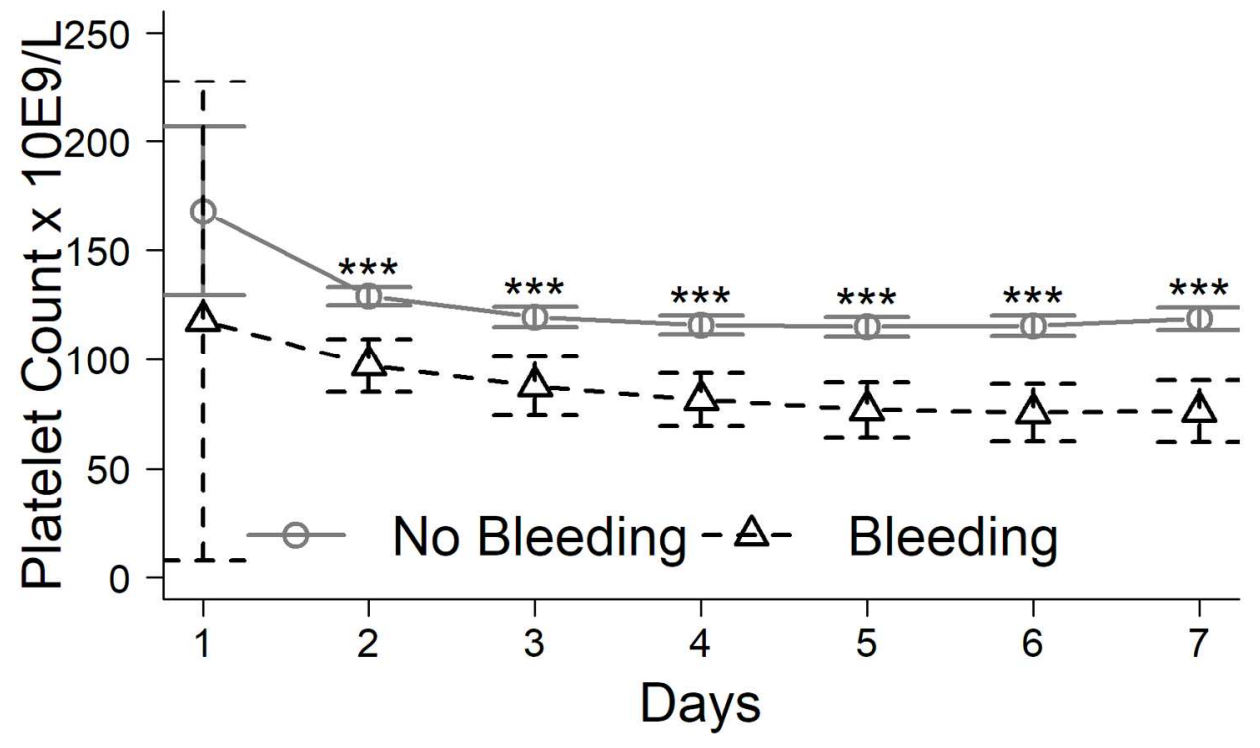

$152 \times 95 \mathrm{~mm}(300 \times 300$ DPI $)$ 


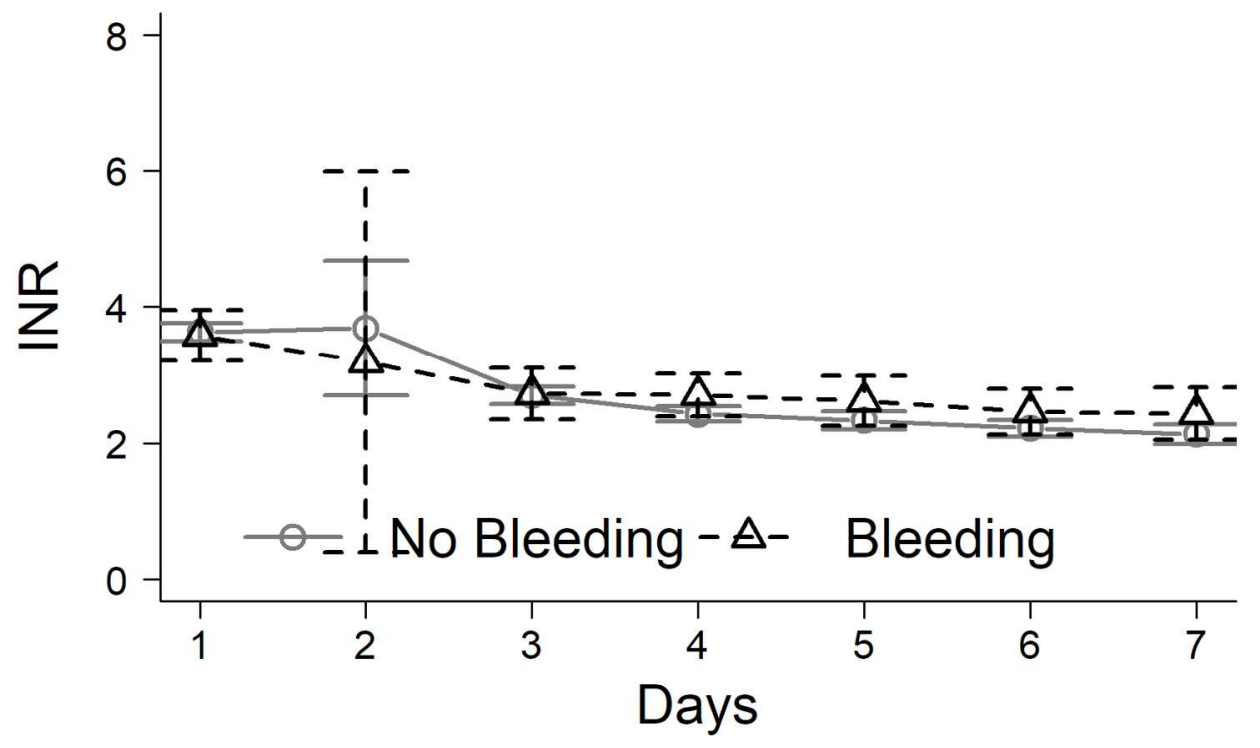

$152 \times 95 \mathrm{~mm}(300 \times 300$ DPI $)$ 


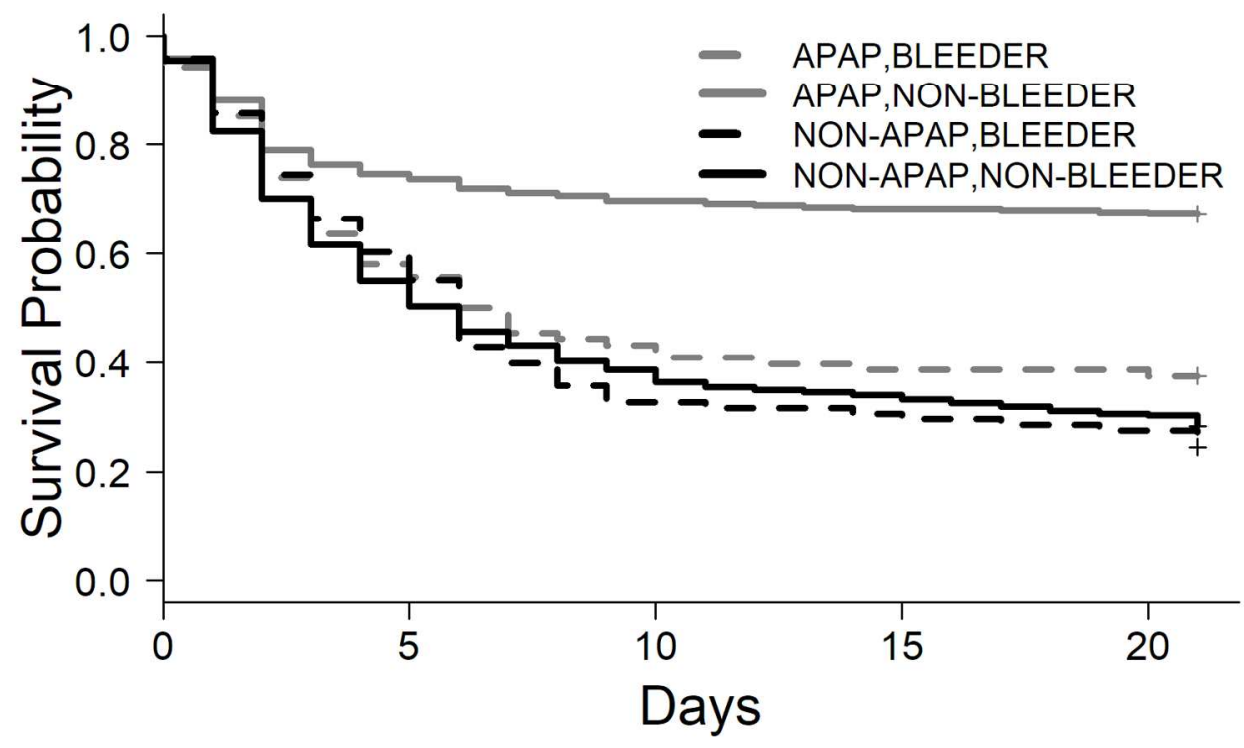

$152 \times 95 \mathrm{~mm}(300 \times 300$ DPI $)$ 


\begin{tabular}{|c|c|c|c|c|}
\hline Clinical Feature & $\mathbf{N}$ & $\begin{array}{c}\text { Included } \\
\mathrm{N}=1770 \\
\mathrm{~N} \pm \mathrm{SD}(\%) \\
\end{array}$ & $\begin{array}{c}\text { Excluded } \\
\mathbf{N}=\mathbf{5 7 5} \\
\mathrm{N} \pm \mathrm{SD}(\%) \\
\end{array}$ & $\mathbf{P}$ \\
\hline \multicolumn{5}{|l|}{ Demographics } \\
\hline Age (Years) & 2345 & $41 \pm 15$ & $40 \pm 15$ & 0.15 \\
\hline Gender ( $\%$ Female) & 2345 & $1221(69.0)$ & $405(70.4)$ & 0.55 \\
\hline APAP Etiology of ALF & 2345 & $798(45.1)$ & $283(49.2)$ & 0.09 \\
\hline \multicolumn{5}{|l|}{ Clinical Features on Admission } \\
\hline Plasma before admission & 2268 & $762(44.3)$ & $205(37.4)$ & 0.005 \\
\hline Anticoagulants on admission & 2345 & $46(2.6)$ & $17(3.0)$ & 0.756 \\
\hline Aspirin on admission & 2345 & $100(5.6)$ & $35(6.1)$ & 0.77 \\
\hline $\operatorname{SIRS}(\% \geq 2)$ & 1780 & $1024(75.1)$ & $286(68.8)$ & 0.013 \\
\hline Encephalopathy Grade 3/4 & 2274 & $848(49.3)$ & $202(36.5)$ & $<0.001$ \\
\hline $\mathrm{INR}^{\wedge}$ & 2025 & $2.8 \pm 2.2$ & $2.5 \pm 1.6$ & 0.001 \\
\hline Platelet Count $\left(\times 10^{9} / \mathrm{L}\right)^{\wedge}$ & 2012 & $124.0 \pm 109.0$ & $137.0 \pm 84.0$ & 0.002 \\
\hline $\mathrm{WBC}\left(\mathrm{x} 10^{9} / \mathrm{L}\right)$ & 2321 & $10.2 \pm 8.3$ & $10.2 \pm 7.5$ & 0.73 \\
\hline Hemoglobin $(\mathrm{g} / \mathrm{dl})$ & 2318 & $10.9 \pm 3.1$ & $11.1 \pm 3.3$ & 0.14 \\
\hline \multicolumn{5}{|c|}{ Clinical Features and Interventions after Admission, Days 1-7 } \\
\hline Bleeding Complication* & 2339 & $187(10.6)$ & $42(7.4)$ & 0.032 \\
\hline RBC Transfusion & 2345 & $651(36.8)$ & $148(25.7)$ & $<0.001$ \\
\hline Plasma Transfusion & 2345 & $994(56.2)$ & $238(41.4)$ & $<0.001$ \\
\hline Platelet Transfusion & 2345 & $435(24.6)$ & $71(12.3)$ & $<0.001$ \\
\hline \multicolumn{5}{|l|}{ Outcomes at Day 21} \\
\hline Liver Transplantation & 2331 & $430(24.5)$ & $117(20.4)$ & 0.051 \\
\hline Died $\dagger$ & 2107 & $599(33.8)$ & $73(21.7)$ & $<0.001$ \\
\hline COD Bleeding $\dagger$ & 672 & $16(2.7)$ & $1(1.4)$ & 1.00 \\
\hline
\end{tabular}

* Excludes $N=6$ subjects with missing bleeding data

$\wedge$ Excludes $N=331$ subjects with missing platelet and/or INR data

$\dagger$ Excludes $N=238$ subjects with unknown 21 day status

Supplemental Table 1. Comparison of patients included and excluded from the study. (COD, cause of death). 


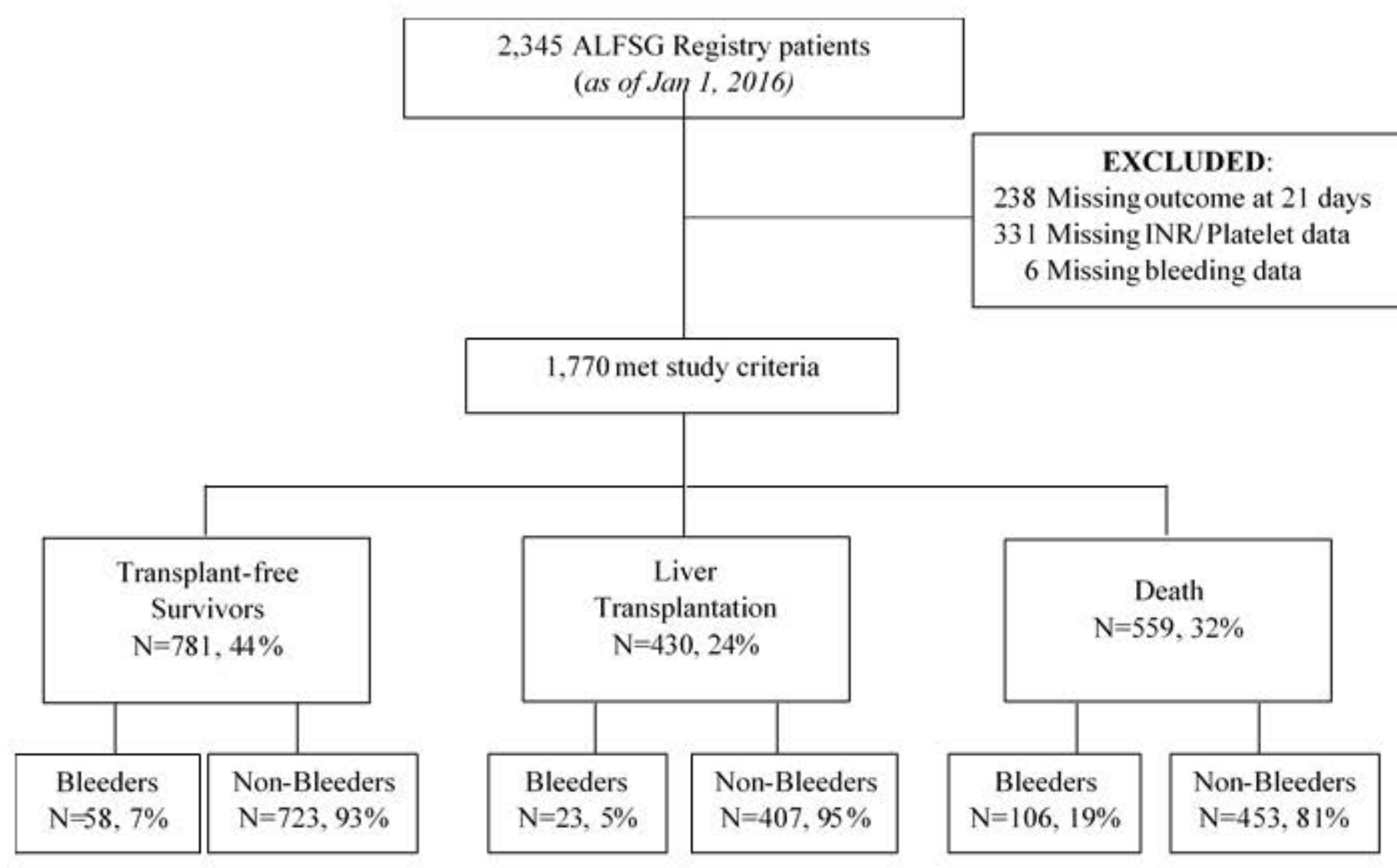

Supplemental Figure 1. Patient accrual according to outcome at day 21 , and distribution of bleeding complications. 


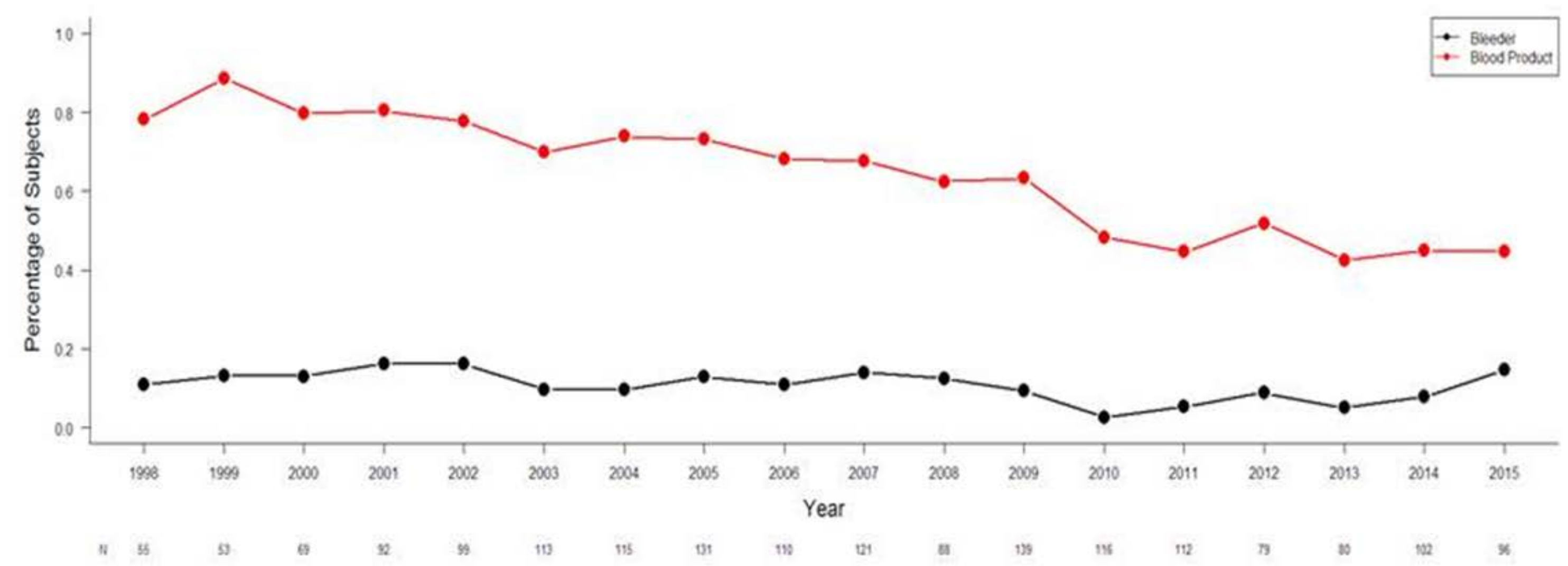

Supplemental Figure 2. Percentage of patients enrolled into the ALF Study Group Registry who received blood products (RBC, plasma, and/or platelets; upper line) and who experienced bleeding complications (lower line) between days 1-7 by year of enrollment. 